\title{
Gain Calibration of Current-to-Voltage Converters
}

\author{
Thomas Larason and C. Cameron Miller \\ National Institute of Standards and Technology, \\ Gaithersburg, MD 20899, USA \\ thomas.larason@nist.gov \\ c.miller@nist.gov \\ Current-to-voltage converters are used in many photometric and radiometric applications. The calibration of current-to-voltage \\ converters at a few input currents is not always sufficient to understand the linearity and the bias of a device. Many devices have \\ structure deviating from a linear response over the operating range of a gain setting. Measurement services that rely on these devices \\ now have decreased uncertainties to a level that requires quantifying the uncertainties and understanding how they propagate. The \\ National Institute of Standards and Technology has developed a system to calibrate the current-to-voltage conversion factor or "gain" \\ and offset of these devices for direct current photocurrents. The equipment used for the calibration is described here, and the results \\ and uncertainties are discussed.
}

Key words: calibration; current amplifier; current-to-voltage converter; low DC current; reference current meter; SI traceable photocurrent; uncertainty.

Accepted: October 24, 2018

Published: November 19, 2018; Current Version: April 14, 2020

https://doi.org/10.6028/jres.123.019

\section{Introduction and Motivation}

Current-to-voltage converters (CVCs) are key elements in photocurrent measurements and are used in many photometric and radiometric applications. For many of these applications, direct current (DC) photocurrents are measured in the range of $100 \mathrm{pA}$ to $1 \mathrm{~mA}$. Calibrating the current-to-voltage conversion factor, or "gain," is straightforward using a commercial current source and a voltmeter and is suitable for most applications requiring standard uncertainties on the order of $0.1 \%$ or higher [1]. However, recent advances in photometric and radiometric applications at the National Institute of Standards and Technology (NIST) have prompted the need for lower uncertainties. This need motivated research to reduce the uncertainty and improve the SI traceability for the calibration of CVCs [1-3]. NIST has developed a calibration system to measure the CVC gain and the offset for DC photocurrents [3,4]. This publication supersedes Ref. [3] and finalizes the uncertainty analysis and description of the calibration service.

There are different methods for calibrating a CVC. A reference CVC may be directly substituted with the CVC device under test (DUT), but to be practical, this method requires automated signal switching that adds noise to the current input for the calibration. The method chosen by the NIST CVC calibration service is to use the reference CVC to calibrate the output current from the current source and to rely on the stability of the current source.

Measuring the CVC gain is not complicated; however, improvement in two areas was necessary for the applications at NIST, including (1) reducing the uncertainty of the current source calibration, and (2) determining the uncertainty of a current source measurement, such as a photodiode, using the calibrated DUT. This paper explains the solutions to both objectives. 


\section{Measurement Theory}

A CVC can be modeled as a simple operational amplifier (op-amp or OA) circuit with a feedback resistor as shown in Fig. 1. The value of the feedback resistor determines the gain of the input current.

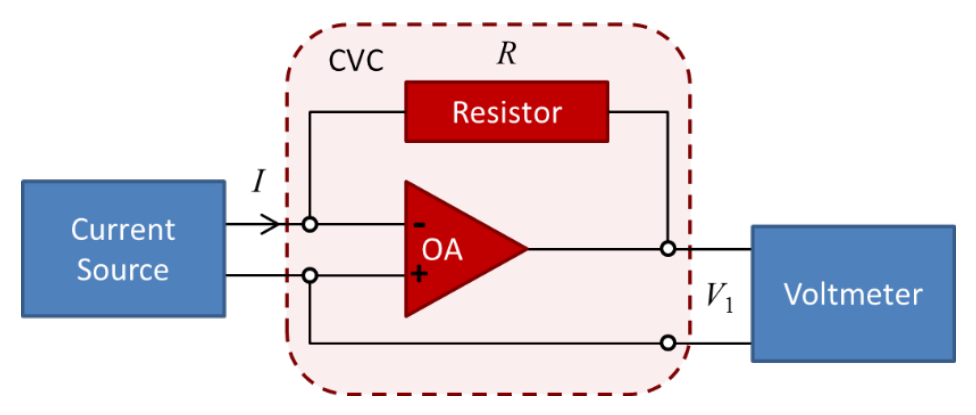

Fig. 1. Current determination with a reference current-to-voltage converter (CVC).

The current $I$ from the current source is

$$
I=\left(V_{1}(I)-V_{1}(I=0)\right) / R
$$

where $V_{1}(I=0)$ is the CVC output voltage for $I=0$, and $R$ is the feedback resistor of the op-amp in the CVC. The voltage subtraction cancels the output offset voltage of the CVC. Using Eq. (1), the output of the current source, $I$, can be measured with a calibrated voltmeter and feedback resistor, $R$. In practice, several values of feedback resistors are used to calibrate the operational range of the current source.

The output voltage of a DUT CVC is $V_{2}$. The gain, $G(I)$, of a gain setting of the DUT is

$$
G(I)=\left(V_{2}(I)-V_{2}(I=0)\right) / I
$$

where $V_{2}(I)$ is the DUT output voltage for input current $I, V_{2}(I=0)$ is the DUT output voltage for $I=0$, and $I$ is the current as determined by Eq. (1). The output offset voltage of the DUT is canceled by the voltage subtraction in Eq. (2).

In practice, $G(I)$ should be measured at several different input currents across the output range of the DUT, typically, from $-10 \mathrm{~V}$ to $10 \mathrm{~V}$ in $0.5 \mathrm{~V}$ steps. CVCs are designed to be linear, so a linear least squares (LLS) weighted fit is used to model the $G(I)$ measurements taken over the operating range of the DUT to provide a single $G_{m}$ for the range. This LLS fit can be expressed as

$$
V=G_{m} I+b
$$

where $V[\mathrm{~V}]$ is the output voltage of the DUT, $G_{m}[\mathrm{~V} / \mathrm{A}]$ is the measured gain, $I[\mathrm{~A}]$ is the input current to the $\mathrm{CVC}$, and $b[\mathrm{~V}]$ is the intercept or offset.

Often, $b$ is much smaller than the uncertainty of the measured output voltage and is ignored. However, for applications requiring the lowest possible uncertainties, $b$ must be measured and considered.

\section{Equipment Description}

The NIST CVC calibration system consists of a precision current source and a voltmeter [5]. The current source is calibrated using the NIST transfer standard CVC (TS CVC) [3]. The TS CVC is a critical element in the calibration traceability and has a smaller uncertainty than was previously achievable. A block diagram and photographs of the CVC calibration system are shown in Fig. 2 and Fig. 3, respectively.

†Symbols used in Equation (3) changed on April 14, 2000, to be consistent with those used in earlier equations, i.e., $V$ for voltage and $I$ for current. This change is carried on throughout the article. 


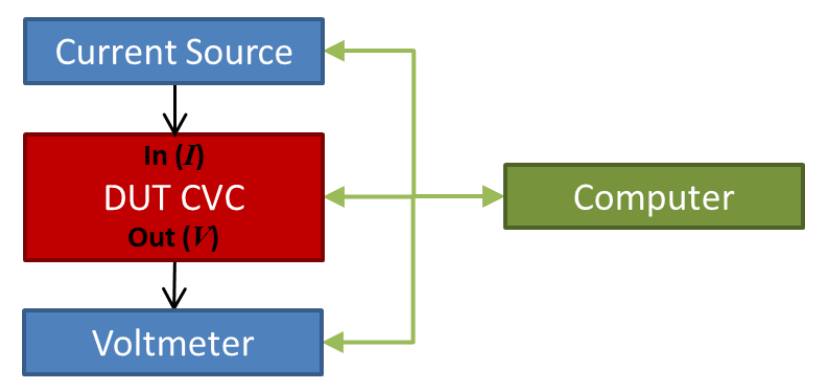

Fig. 2. Block diagram of the NIST CVC calibration system.
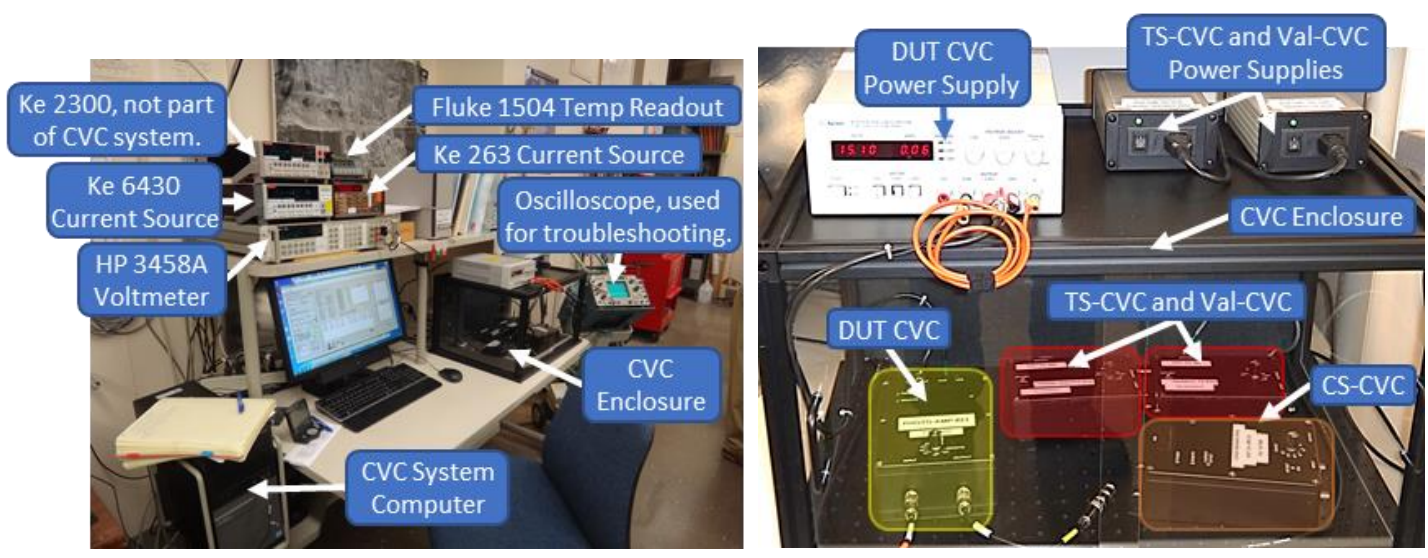

Fig. 3. Photographs of the NIST CVC calibration system. The entire calibration system, including current sources, voltmeter, computer, and an enclosure for the CVCs, is shown on the left. A close-up of the enclosure showing several CVCs, including a DUT, check standard (CS), TS CVC, and validation TS CVC (Val CVC), is shown on the right, which look similar since the enclosures are the same.

\subsection{Transfer Standard Current-to-Voltage Converter (TS CVC)}

The basic op-amp design and construction of the TS CVC were described in Refs. [3, 5]. The feedback resistors are precious-metal-oxide film-type resistors and were selected after characterizing various parameters, such as temperature coefficient, voltage coefficient, and drift, to find the most stable and closest to nominal value resistance.

A unique factor in the NIST TS CVC design is the capability to isolate the resistors by removing jumpers from the circuit board (see Fig. 4 and Fig. 5). This allows the resistors to be measured in situ, together with the parallel resistances of the circuit board, rotary-gain switch, and feedback capacitors.

The TS CVC is a custom device built to NIST specifications. A second, nearly identical device was constructed in tandem with the TS CVC. Both devices are typically calibrated together by the NIST Quantum Measurement Division (QMD). The second device is referred to as the validation TS CVC (Val CVC) and is used, as the name indicates, to validate the CVC calibration system. 


\section{Journal of Research of the National Institute of Standards and Technology}

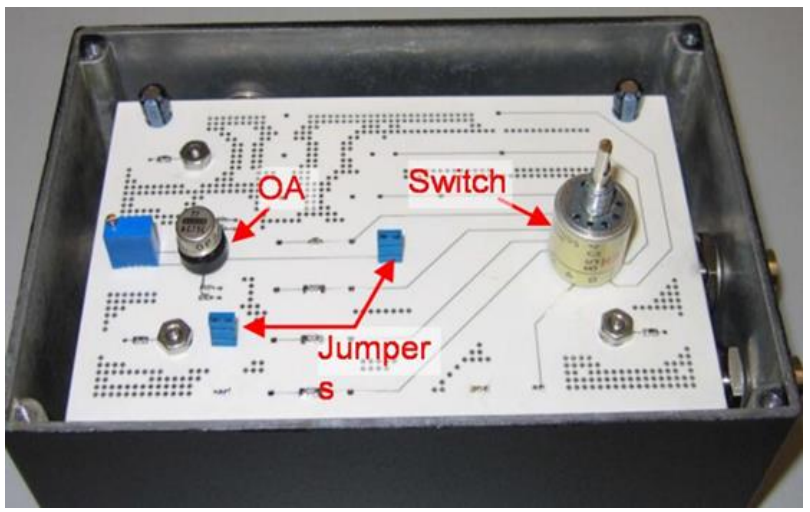

Fig. 4. Internal view of the NIST TS CVC. The operational amplifier (OA) is shown on the left, with the rotary switch for resistance (gain setting) selection on the right. The jumper plugs isolate the OA when the resistances are measured. The resistors are mounted on the reverse side of the board [2].

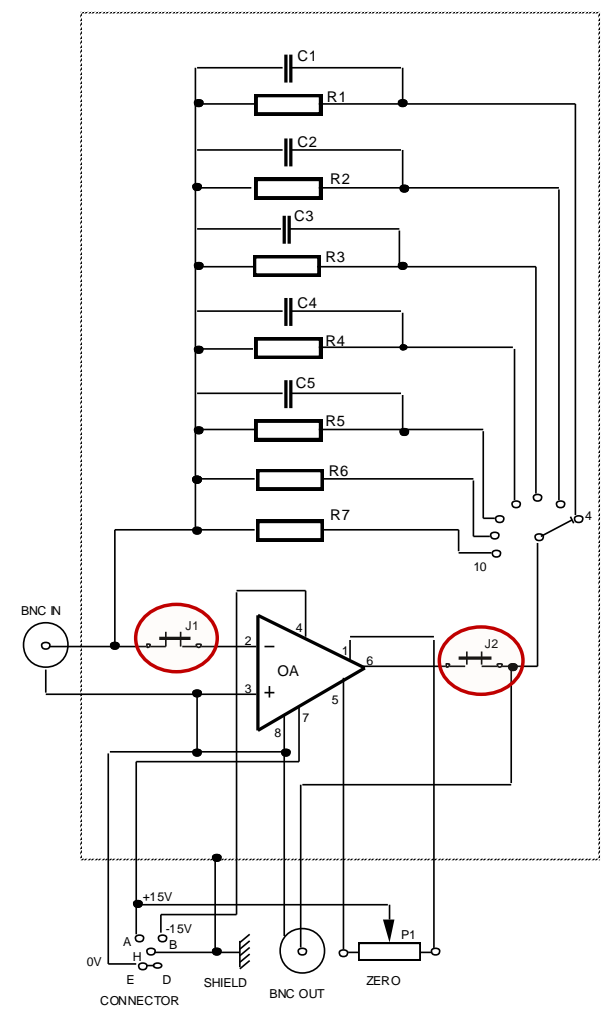

Fig. 5. Circuit diagram of the NIST TS CVC [3, 5]. Jumper plugs, J1 and J2, are removed to isolate the OA from the resistors when they are calibrated in situ.

\subsection{Current Source and Voltmeter}

The CVC calibration system utilizes two different current sources. A Keithley model 263

Calibrator/Source ${ }^{1}$ is used for typical calibrations, and a Keithley model 6430 SourceMeter can be used for calibrations requiring femtoampere currents. The voltmeter used with the CVC calibration system is a Hewlett-Packard 3458A with the high-stability reference (option 002).

${ }^{1}$ Certain commercial equipment, instruments, or materials are identified in this paper to foster understanding. Such identification does not imply recommendation or endorsement by the National Institute of Standards and Technology, nor does it imply that the materials or equipment identified are necessarily the best available for the purpose. Other products may be found that work as well or better. 


\section{Calibration SI Traceability}

The SI traceability chain is shown in Fig. 6. The DUTs are calibrated with a current source and a voltmeter. The current source is calibrated using the NIST TS CVC [3, 5]. The TS CVC's feedback resistors are calibrated (in situ) by comparison to NIST working standards calibrated in terms of the quantum Hall effect. The voltmeter DC voltage is calibrated by comparison to a NIST 10 V Josephson voltage standard (JVS). Both the resistance and DC voltage calibrations are carried out by the NIST QMD and represent direct realizations of the ohm and volt under the new SI definitions.

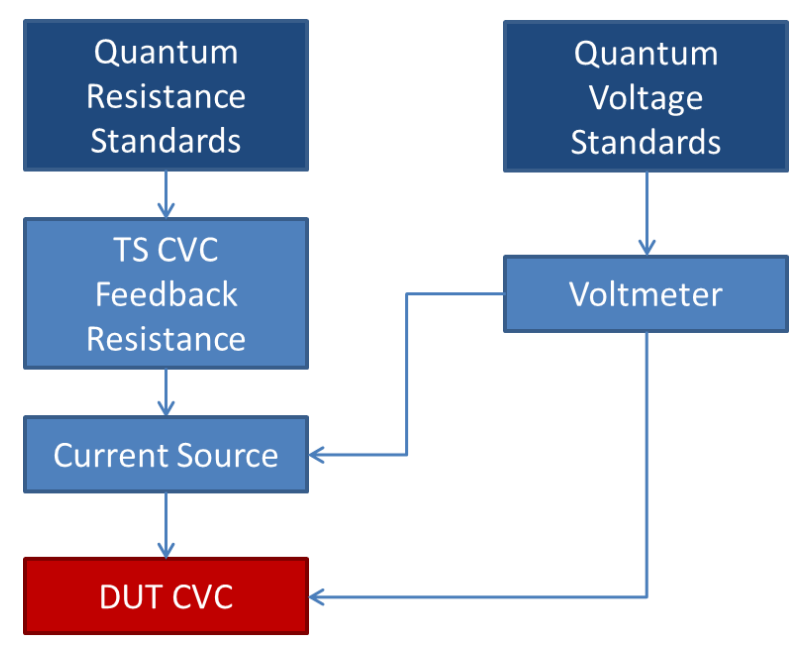

Fig. 6. SI traceability for the NIST CVC calibration system.

\subsection{Calibration of Transfer Standard CVC Feedback Resistors}

Calibration of the feedback resistors is a key step in the traceability. As mentioned above, the TS CVC resistors can be isolated by removing jumpers from the circuit board, allowing the resistors to be measured in situ, together with any parallel resistances of the circuit board, rotary-gain switch, and feedback capacitors. The resistance of each gain setting is calibrated by comparison to NIST resistance working standards using 2-terminal to 4-terminal adapters at the BNC connectors. The NIST resistance standards are traceable to the quantized Hall resistance (QHR) [6].

\subsection{Voltmeter Calibration}

The voltmeter is calibrated for voltage gain by evaluating its DC voltage readings compared with that generated by a $10 \mathrm{~V}$ JVS [7]. The internal voltage reference for the voltmeter is calibrated by use of a solidstate voltage standard, which in turn is calibrated by use of the $10 \mathrm{~V} \mathrm{JVS}$.

\subsection{Current Source Calibration}

The output current of the current source is input to the TS CVC, and the output voltage from the TS CVC is measured by the voltmeter. Using the calibrated feedback resistors of the TS CVC, the output current of the current source can be calculated using $I=V / R$. This is generally done over a decade range of the current source using a single gain setting of the TS CVC for each current range. A calibration table is generated for each current range used for DUT calibrations. The electrical connections are 2-wire connectors using typical BNC cables. The differences between 2- and 4-wire measurements are accounted for in the current source repeatability. 


\section{Uncertainty Evaluation}

The uncertainty in the DUT measured gain in the CVC calibration system depends on several factors, which will be discussed in detail in this section. The uncertainty values shown are only for illustration and can vary by DUT type (model). There are also small differences in the uncertainties, depending on which current source is used for the measurements. Uncertainties propagated using the Keithley 263 and 6430 current sources are given below.

\subsection{Transfer Standard CVC}

Typical calibration results and uncertainty for the feedback resistors of the TS CVC and the Val CVC are summarized in Table 1. The resistor serial numbers are prefaced by 1010 for the TS CVC and 1000 for the Val CVC.

Table 1. Calibrated feedback resistance values for the TS CVC (SN: 1010) and Val CVC (SN: 1000).

\begin{tabular}{lcccccc}
\hline $\begin{array}{c}\text { Resistor Serial } \\
\text { No. }\end{array}$ & $\begin{array}{c}\text { Nominal Value } \\
(\Omega)\end{array}$ & $\begin{array}{c}\text { Calibration } \\
\text { Temp. }\left({ }^{\circ} \mathrm{C}\right)\end{array}$ & $\begin{array}{c}\text { Calibration } \\
\text { Voltage }(\mathrm{V})\end{array}$ & $\begin{array}{c}\text { Correction } \\
\left(\times 10^{-6}\right)\end{array}$ & $\begin{array}{c}\text { Exp. Uncert. } \\
(k=2)\left(\times 10^{-6}\right)\end{array}$ & $\begin{array}{c}\text { Change/year } \\
\left(\times 10^{-6}\right)\end{array}$ \\
\hline $1000-10 \mathrm{~K}$ & $1 \times 10^{4}$ & 22.99 & $10 \mathrm{~V}, 1 \mathrm{~mA}$ & 17.4 & 0.3 & 2.27 \\
$1010-10 \mathrm{~K}$ & $1 \times 10^{4}$ & 22.98 & $10 \mathrm{~V}, 1 \mathrm{~mA}$ & 43.8 & 0.3 & 2.13 \\
$1000-100 \mathrm{~K}$ & $1 \times 10^{5}$ & 23.00 & 10 & 57.0 & 0.8 & 1.19 \\
$1010-100 \mathrm{~K}$ & $1 \times 10^{5}$ & 23.00 & 10 & 91.2 & 0.8 & 1.45 \\
$1000-1 \mathrm{M}$ & $1 \times 10^{6}$ & 23.00 & 10 & 46.2 & 0.8 & 3.31 \\
$1010-1 \mathrm{M}$ & $1 \times 10^{6}$ & 23.00 & 10 & 55.4 & 0.8 & 3.74 \\
$1000-10 \mathrm{M}$ & $1 \times 10^{7}$ & 22.99 & 10 & 147 & 6 & 7.61 \\
$1010-10 \mathrm{M}$ & $1 \times 10^{7}$ & 22.99 & 10 & 100 & 6 & 3.81 \\
$1000-100 \mathrm{M}$ & $1 \times 10^{8}$ & 22.98 & 10 & 57 & 6 & 7.79 \\
$1010-100 \mathrm{M}$ & $1 \times 10^{8}$ & 22.98 & 10 & 113 & 6 & 6.23 \\
$1000-1 \mathrm{G}$ & $1 \times 10^{9}$ & 23.00 & 10 & 841 & 18 & 2.08 \\
$1010-1 \mathrm{G}$ & $1 \times 10^{9}$ & 23.00 & 10 & -282 & 18 & 1.90 \\
$1000-10 \mathrm{G}$ & $1 \times 10^{10}$ & 23.01 & 10 & 857 & 50 & -6.92 \\
$1010-10 \mathrm{G}$ & $1 \times 10^{10}$ & 23.01 & 10 & -18 & 50 & -5.19 \\
\hline
\end{tabular}

\subsection{Current Source Calibration}

The uncertainty of the current source calibration has two terms. The first term is an absolute uncertainty expressed in SI units that is independent of the current level, and it represents a bias in the current source. The second term is a relative term expressed as a percentage that is dependent on the current level. The uncertainty is the square root of the sum of the squares (RSS) of both terms once the second term is converted to an absolute value by multiplying by the measured current. An example uncertainty budget for the DC current measurement of the Keithley 6430 current source using all ranges of the TS CVC following Eq. (1) is shown in Table 2 and Table 3. As the current level is decreased, higher gain settings for the TS CVC are required, introducing different levels of uncertainty. Table 2 is the absolute term, and Table 3 is the relative term. A similar set of tables was generated for the Keithley 263 current source, shown in Table 4 and Table 5. 


\section{Journal of Research of the National Institute of Standards and Technology}

Table 2. Absolute term for the standard uncertainty budget for the current produced by the Keithley 6430 DC current source using the TS CVC (Eq. 1).

\begin{tabular}{|c|c|c|c|c|c|c|c|c|}
\hline & & \multicolumn{7}{|c|}{ Absolute standard uncertainty $\left[\mathrm{A} \times 10^{-6}\right]$} \\
\hline Uncertainty components & Type & $\begin{array}{c}\text { Range } \\
1 \times 10^{4} \\
\text { V/A }\end{array}$ & $\begin{array}{c}1 \times \\
10^{5} \\
\text { V/A }\end{array}$ & $\begin{array}{l}1 \times 10^{6} \\
\text { V/A }\end{array}$ & $\begin{array}{l}1 \times 10^{7} \\
\mathrm{~V} / \mathrm{A}\end{array}$ & $\begin{array}{r}1 \times \\
10^{8} \\
\text { V/A }\end{array}$ & $\begin{array}{c}1 \times 10^{9} \\
\text { V/A }\end{array}$ & $\begin{array}{c}1 \times \\
10^{10} \\
V / A\end{array}$ \\
\hline Feedback resistance & $\mathrm{B}$ & $<0.01$ & $<0.01$ & $<0.01$ & $<0.01$ & $<0.01$ & $<0.01$ & $<0.01$ \\
\hline Measurement noise & A & 3.95 & 3.87 & 45.3 & 45.7 & 58.4 & 365 & 4217 \\
\hline Voltage measurement & B & 0.14 & 0.14 & 0.14 & 0.14 & 0.14 & 0.14 & 0.14 \\
\hline Repeatability & A & $<0.01$ & $<0.01$ & $<0.01$ & $<0.01$ & $<0.01$ & $<0.01$ & $<0.01$ \\
\hline Long-term drift of feedback resistance & A & $<0.01$ & $<0.01$ & $<0.01$ & $<0.01$ & $<0.01$ & $<0.01$ & $<0.01$ \\
\hline Loop gain & $\mathrm{B}$ & $<0.01$ & $<0.01$ & $<0.01$ & $<0.01$ & $<0.01$ & $<0.01$ & $<0.01$ \\
\hline $\begin{array}{l}\text { Combined absolute standard uncertainty term } \\
\text { of } I \text { measurement }\end{array}$ & & 3.95 & 3.87 & 45.3 & 45.7 & 58.4 & 365 & 4217 \\
\hline
\end{tabular}

Table 3. Relative term for the standard uncertainty budget for the current produced by the Keithley 6430 DC current source using the TS CVC (Eq. 1)

\begin{tabular}{|c|c|c|c|c|c|c|c|c|}
\hline & & \multicolumn{7}{|c|}{ Relative standard uncertainty $\left[\times 10^{-6}\right]$} \\
\hline Uncertainty components & Type & $\begin{array}{c}\text { Range } \\
1 \times 10^{4} \\
\text { V/A }\end{array}$ & $\begin{array}{c}1 \times 10^{5} \\
\mathrm{~V} / \mathrm{A}\end{array}$ & $\begin{array}{c}1 \times 10^{6} \\
\mathrm{~V} / \mathrm{A}\end{array}$ & $\begin{array}{c}1 \times \\
10^{7} \\
\text { V/A } \\
\end{array}$ & $\begin{array}{l}1 \times \\
10^{8} \\
\text { V/A } \\
\end{array}$ & $\begin{array}{c}1 \times 10^{9} \\
\mathrm{~V} / \mathrm{A}\end{array}$ & $\begin{array}{c}1 \times \\
10^{10} \\
\text { V/A } \\
\end{array}$ \\
\hline Feedback resistance & $\mathrm{B}$ & 0.15 & 0.40 & 0.40 & 3.00 & 3.00 & 9.00 & 25.0 \\
\hline Measurement noise & A & 0.18 & 0.18 & 2.86 & 2.76 & 2.88 & 3.53 & 9.24 \\
\hline Voltage measurement & $\mathrm{B}$ & 0.01 & 0.01 & 0.01 & 0.01 & 0.01 & 0.01 & 0.01 \\
\hline Repeatability & A & 16.5 & 18.2 & 20.1 & 21.0 & 35.7 & 33.4 & 195 \\
\hline Long-term drift of feedback resistance & A & 2.13 & 1.45 & 3.74 & 3.81 & 6.23 & 1.9 & 5.19 \\
\hline Loop gain & B & 2.00 & 2.00 & 2.00 & 2.00 & 2.00 & 2.00 & 2.00 \\
\hline $\begin{array}{l}\text { Combined relative standard uncertainty term } \\
\text { of } I \text { measurement }\end{array}$ & & 16.8 & 18.4 & 20.7 & 21.8 & 36.6 & 34.9 & 197 \\
\hline
\end{tabular}

Table 4. Absolute term for the standard uncertainty budget for the current produced by the Keithley 263 DC current source using the TS CVC (Eq. 1).

\begin{tabular}{|c|c|c|c|c|c|c|c|c|}
\hline & & \multicolumn{7}{|c|}{ Absolute standard uncertainty $\left[\mathrm{A} \times 10^{-6}\right]$} \\
\hline Uncertainty components & Type & $\begin{array}{c}\text { Range } \\
1 \times 10^{4} \\
\text { V/A }\end{array}$ & $\begin{array}{c}1 \times 10^{5} \\
\mathrm{~V} / \mathrm{A}\end{array}$ & $\begin{array}{c}1 \times 10^{6} \\
\mathrm{~V} / \mathrm{A}\end{array}$ & $\begin{array}{c}1 \times \\
10^{7} \\
\text { V/A }\end{array}$ & $\begin{array}{c}1 \times \\
10^{8} \\
\text { V/A }\end{array}$ & $\begin{array}{c}1 \times 10^{9} \\
\mathrm{~V} / \mathrm{A}\end{array}$ & $\begin{array}{c}1 \times \\
10^{10} \\
\mathrm{~V} / \mathrm{A}\end{array}$ \\
\hline Feedback resistance & $\mathrm{B}$ & $<0.01$ & $<0.01$ & $<0.01$ & $<0.01$ & $<0.01$ & $<0.01$ & $<0.01$ \\
\hline Measurement noise & A & 7.17 & 26.3 & 30.4 & 26.9 & 43.6 & 40.9 & 281 \\
\hline Voltage measurement & B & 0.14 & 0.14 & 0.14 & 0.14 & 0.14 & 0.14 & 0.14 \\
\hline Repeatability & A & $<0.01$ & $<0.01$ & $<0.01$ & $<0.01$ & $<0.01$ & $<0.01$ & $<0.01$ \\
\hline Long-term drift of feedback resistance & A & $<0.01$ & $<0.01$ & $<0.01$ & $<0.01$ & $<0.01$ & $<0.01$ & $<0.01$ \\
\hline Loop gain & $\mathrm{B}$ & $<0.01$ & $<0.01$ & $<0.01$ & $<0.01$ & $<0.01$ & $<0.01$ & $<0.01$ \\
\hline $\begin{array}{l}\text { Combined absolute standard uncertainty } \\
\text { term of } I \text { measurement }\end{array}$ & & 7.18 & 26.3 & 30.4 & 26.9 & 43.6 & 40.9 & 281 \\
\hline
\end{tabular}

Table 5. Relative term for the standard uncertainty budget for the current produced by the Keithley 263 DC current source using the TS CVC (Eq. 1)

\begin{tabular}{l|r|r|r|r|r|c|r|r}
\hline & \multicolumn{7}{c}{ Relative standard uncertainty $\left[\times 10^{-6}\right]$} \\
\hline & & $\begin{array}{c}\text { Range } \\
1 \times 10^{4} \\
\text { Vncertainty components }\end{array}$ & $\begin{array}{c}1 \times 10^{5} \\
\text { V/A }\end{array}$ & $\begin{array}{c}1 \times 10^{6} \\
\text { V/A }\end{array}$ & $\begin{array}{c}1 \times \\
10^{7} \\
\text { V/A }\end{array}$ & $\begin{array}{c}1 \times \\
10^{8} \\
\text { V/A }\end{array}$ & $\begin{array}{c}1 \times 10^{9} \\
\text { V/A }\end{array}$ & $\begin{array}{c}1 \times \\
10^{10} \\
\text { V/A }\end{array}$ \\
\hline Feedback resistance & $\mathrm{B}$ & 0.15 & 0.40 & 0.40 & 3.00 & 3.00 & 9.00 & 25.0 \\
\hline Measurement noise & $\mathrm{A}$ & 0.25 & 0.90 & 0.93 & 0.92 & 1.30 & 6.20 & 45.6 \\
\hline Voltage measurement & $\mathrm{B}$ & 0.01 & 0.01 & 0.01 & 0.01 & 0.01 & 0.01 & 0.01 \\
\hline Repeatability & $\mathrm{A}$ & 1.21 & 5.16 & 3.53 & 3.66 & 4.46 & 9.22 & 53.7 \\
\hline Long-term drift of feedback resistance & $\mathrm{A}$ & 2.13 & 1.45 & 3.74 & 3.81 & 6.23 & 1.9 & 5.19 \\
\hline Loop gain & $\mathrm{B}$ & 2.00 & 2.00 & 2.00 & 2.00 & 2.00 & 2.00 & 2.00 \\
\hline $\begin{array}{l}\text { Combined relative standard uncertainty term } \\
\text { of } I \text { measurement }\end{array}$ & & 3.18 & 5.81 & 5.61 & 6.46 & 8.57 & 14.6 & 75.0 \\
\hline
\end{tabular}


The DC current source uncertainty components listed in Table 2 to Table 5 include both those derived from Eq. (1) and additional systematic components (voltmeter calibration, reproducibility, long-term drift, and loop gain). Each component is explained below.

Feedback resistance is the combined standard uncertainty from the QMD calibration report, i.e., one half of the expanded uncertainty $(k=2)$; see Table 1 . This is only a relative component (Table 3 and Table 5 ); there is no absolute uncertainty component (Table 2 and Table 4) for the feedback resistance.

Measurement noise is the average "noise" of multiple samples. In Table 2 and Table 4, the measurement noise is defined by the standard deviation of the offset $(I=0)$ measurement. In Table 3 and Table 5, the average of the signal standard deviation of the mean divided by the mean (SDOM/Mean) [\%] is the measurement noise.

Voltage measurement is from the QMD calibration report. The mean voltmeter gain error from the LLS fit in the report is rounded up to a value that covers yearly variation in the calibration. This is not a significant contributor to the uncertainty.

Repeatability is the average relative standard deviation of the current correction of multiple measurements. Typically, three to five measurements are taken over one or two days when calibrating the current source. The TS CVC output noise is difficult to separate from the measurement-to-measurement variation, so they are considered as one term for analysis.

Long-term drift of feedback resistance is the change in the resistance value between calibrations for a 12 month period. This value is from the last column in Table 1. As the number of calibrations increase, this drift is expected to decrease, as is typical for resistors, and then the drift may be modelled to reduce this uncertainty component. This is only a relative component (Table 3 and Table 5); there is no absolute standard uncertainty component (Table 2 and Table 4) for the feedback resistance drift.

Loop gain is determined by the current source and TS CVC op-amp impedances [3, 5].

\subsection{DUT Calibration}

\subsubsection{DUT Gain Calibration}

An example uncertainty budget for the gain of a DUT following Eq. (2) is shown in Table 6 (absolute term) and Table 7 (relative term). The uncertainty is the RSS of both terms once the second term is converted to an absolute gain value by multiplying by the measured current. These tables vary by DUT model. For efficiency, the values in the table were determined after evaluating several DUTs of the same model, and these values were used for subsequent DUTs of this model if the measurement noise was less than the values in the tables. A similar set of tables was generated for the Keithley 6430 current source (not presented).

Table 6. Absolute term for the standard uncertainty budget of the current-to-voltage conversion gain $[G(I)]$ of a DUT using the Keithley 263 DC current source.

\begin{tabular}{|c|c|c|c|c|c|c|c|}
\hline & & \multicolumn{6}{|c|}{ Absolute standard uncertainty [V/A $\left.\times 10^{-6}\right]$} \\
\hline Uncertainty components & Type & $\begin{array}{c}\text { Range } 1 \\
\times 10^{4} \\
\text { V/A }\end{array}$ & $\begin{array}{c}1 \times 10^{5} \\
\text { V/A }\end{array}$ & $\begin{array}{c}1 \times 10^{6} \\
\text { V/A }\end{array}$ & $\begin{array}{c}1 \times 10^{7} \\
\mathrm{~V} / \mathrm{A}\end{array}$ & $\begin{array}{c}1 \times 10^{8} \\
\mathrm{~V} / \mathrm{A}\end{array}$ & $\begin{array}{c}1 \times 10^{9} \\
\mathrm{~V} / \mathrm{A}\end{array}$ \\
\hline Current & $\mathrm{B}$ & 7.18 & 26.3 & 30.4 & 26.9 & 43.6 & 40.9 \\
\hline Measurement noise & A & 11.2 & 22.6 & 32.7 & 25.9 & 41.2 & 32.4 \\
\hline Voltage measurement & $\mathrm{B}$ & 0.14 & 0.14 & 0.14 & 0.14 & 0.14 & 0.14 \\
\hline Reproducibility (6 months) & A & $<0.01$ & $<0.01$ & $<0.01$ & $<0.01$ & $<0.01$ & $<0.01$ \\
\hline Loop gain & $\mathrm{B}$ & $<0.01$ & $<0.01$ & $<0.01$ & $<0.01$ & $<0.01$ & $<0.01$ \\
\hline $\begin{array}{l}\text { Combined absolute standard uncertainty term } \\
\text { of } G(I) \text { measurement }\end{array}$ & & 13.3 & 34.7 & 44.6 & 37.4 & 60.0 & 52.2 \\
\hline
\end{tabular}




\section{Journal of Research of the National Institute of Standards and Technology}

Table 7. Relative term for the standard uncertainty budget of the current-to-voltage conversion gain $[G(I)]$ of a DUT using the Keithley 263 DC current source.

\begin{tabular}{l|r|r|r|r|r|r|r}
\hline & \multicolumn{6}{|c}{ Relative standard uncertainty $\left[\times 10^{-6}\right]$} \\
\hline & & $\begin{array}{c}\text { Range 1 } \\
\times 10^{4}\end{array}$ & $\begin{array}{c}1 \times 10^{5} \\
\text { V/A }\end{array}$ & $\begin{array}{c}1 \times 10^{6} \\
\text { V/A }\end{array}$ & $\begin{array}{c}1 \times 10^{7} \\
\text { V/A }\end{array}$ & $\begin{array}{c}1 \times 10^{8} \\
\text { V/A }\end{array}$ & $\begin{array}{c}1 \times 10^{9} \\
\text { V/A }\end{array}$ \\
\hline Uncertainty components & B & 3.18 & 5.81 & 5.61 & 6.46 & 8.57 & 14.6 \\
\hline Current & $\mathrm{A}$ & 0.19 & 0.89 & 0.85 & 0.88 & 1.33 & 5.52 \\
\hline Measurement noise & $\mathrm{B}$ & 0.01 & 0.01 & 0.01 & 0.01 & 0.01 & 0.01 \\
\hline Voltage measurement & $\mathrm{A}$ & 13.4 & 10.9 & 13.8 & 14.4 & 8.93 & 78.0 \\
\hline Reproducibility (6 months) & $\mathrm{B}$ & 2.00 & 2.00 & 2.00 & 2.00 & 2.00 & 2.00 \\
\hline Loop gain & & 13.9 & 12.5 & 15.05 & 15.93 & 12.6 & 79.6 \\
\hline $\begin{array}{l}\text { Combined relative standard uncertainty term } \\
\text { of } G(I) \text { measurement }\end{array}$ & & & & & & & \\
\hline
\end{tabular}

The DUT gain uncertainty components are:

- Current is the combined standard uncertainty from the current source calibration, i.e., Table 4 and Table 5 for the Keithley 263 DC current source.

- Measurement noise is the average "noise" of multiple samples. In Table 6, the measurement noise is defined by the standard deviation of the offset $(I=0)$ measurement. In Table 7, the average of the signal standard deviation of the mean divided by the mean (SDOM/Mean) [\%] is the measurement noise.

- Voltage measurement is from the QMD calibration report. The mean voltmeter gain error from the LLS fit in the report is rounded up to a value that covers the yearly variation of the calibration. This is not a significant contributor to the uncertainty.

- Reproducibility (6 months) is the drift in the current source over the period of 6 months. It is the RSS of the difference over 6 months for all points except the zero-current point.

- Loop gain is determined by the current source and TS CVC op-amp impedances [3,5].

\subsubsection{DUT Gain and Offset Calibration (Using LLS Weighted Fit) Uncertainty}

As stated earlier, an LLS weighted fit is used to determine the gain, $G_{m}$, and offset, $b$, for an amplifier range. Example standard uncertainties for the DUT gain and offset using a LLS weighted fit are shown in Table 8. This table varies by DUT model. The LLS weighted fit is calculated using the relative and absolute measurement standard uncertainties as weighting factors (i.e., Table 6 and Table 7 if the Keithley 263 was used as the current source). For efficiency, the values in the table are determined after evaluating several DUTs of the same model, and these values are used for subsequent DUTs of this model if the measurement noise is less than the values in Table 4 (absolute term) and Table 5 (relative term) if the Keithley 6430 is used or Table 6 (absolute term) and Table 7 (relative term) if the Keithley 263 is used.

Table 8. Example DUT gain, offset, and standard uncertainties using the Keithley 263 DC current source.

\begin{tabular}{l|r|r|r|r|r|r}
\hline \multicolumn{1}{c|}{} & \multicolumn{5}{c}{ Linear Least Squares Weighted Fit $\left(V=G_{m} I+b\right)$} \\
\hline \multicolumn{1}{c|}{ Range Setting ${ }^{\mathrm{a}}$} & $1 \times 10^{4} \mathrm{~V} / \mathrm{A}$ & $1 \times 10^{5} \mathrm{~V} / \mathrm{A}$ & $1 \times 10^{6} \mathrm{~V} / \mathrm{A}$ & $1 \times 10^{7} \mathrm{~V} / \mathrm{A}$ & $1 \times 10^{8} \mathrm{~V} / \mathrm{A}$ & $1 \times 10^{9} \mathrm{~V} / \mathrm{A}$ \\
\hline Gain $\left(G_{m}\right)[\mathrm{V} / \mathrm{A}]$ & -10001.0546 & -100006.069 & -1000011.9 & -10001176 & -100012214 & -1000340981 \\
\hline Gain $u\left(G_{m}\right)[\mathrm{V} / \mathrm{A}]$ & 0.0068 & 0.135 & 1.39 & 14.5 & 204 & $-2.63 \mathrm{E}-05$ \\
\hline Offset $(b)[\mathrm{V}]$ & $-1.21 \mathrm{E}-05$ & $-1.88 \mathrm{E}-05$ & $-1.92 \mathrm{E}-05$ & $-2.24 \mathrm{E}-05$ & $-1.74 \mathrm{E}-05$ \\
\hline Offset $u(b)[\mathrm{V}]$ & $2.2 \mathrm{E}-06$ & $5.9 \mathrm{E}-06$ & $6.4 \mathrm{E}-06$ & $6.2 \mathrm{E}-06$ & $9.3 \mathrm{E}-06$ & $1.2 \mathrm{E}-05$ \\
\hline
\end{tabular}

${ }^{\text {a }}$ Gain $\left(G_{m}\right)$ [V/A] is the slope determined by an LLS weighted fit. The LLS is weighted by the relative and absolute measurement standard uncertainties.

Gain $u\left(G_{m}\right)$ [V/A] is the standard uncertainty in the gain $\left(G_{m}\right)$.

Offset $(b)[\mathrm{V}]$ is the intercept determined by an LLS weighted fit.

Offset $u(b)[\mathrm{V}]$ is the standard uncertainty in the offset $(b)$.

Note: The offset, $b$, is different than the "dark" or $I=0$ signal voltage, which is sometimes referred to as an "offset." The offset is a stray voltage that is constant in the system.

In practice, the input current to the DUT is the variable of interest. In this case, Eq. (3) can be $\dagger$ rewritten as

Reference changed to Eq. (3) on April 14, 2020. 


$$
I=(V-b) / G_{m},
$$

where $I[\mathrm{~A}]$ is the input current to the CVC, $V[\mathrm{~V}]$ is the output voltage of the DUT, $b[\mathrm{~V}]$ is the intercept or offset, and $G_{m}[\mathrm{~V} / \mathrm{A}]$ is the measured gain.

The standard uncertainties for the gain and offset are provided in Table 8. The standard uncertainty for the output voltage, $y$, has several uncertainty components, including the uncertainty in the calibration of the voltmeter used and the standard deviation of the voltage measurements used to calculate the average output voltage. Another uncertainty component that may dominate the uncertainty of the output voltage is the uncertainty resulting from the fitting error in the gain and offset determination.

Figure 7 shows the residuals for the linear fit to the data for a DUT operating with a $G_{m}$ [V/A] of $10^{4}$. For the data points at $-0.0095 \mathrm{~A},-0.0005 \mathrm{~A}$, and $0.0002 \mathrm{~A}$, the standard uncertainty is shown as a single bar. The oblong-shaped dot at these points represents the variability in the measurements. The residual structure is repeatable, demonstrating that a linear fit is not the best choice of model. The dashed line represents the confidence band for the results of the weighted linear fit. The gain and offset will fall within this band. The confidence band at a given current, $I^{*}$, is calculated by

$$
C I\left(I^{*}\right)=t_{\alpha, n-2} \cdot \sqrt{\boldsymbol{a}^{T} \boldsymbol{C a}},
$$

where $t_{\alpha, n-2}$ is the Student's $t$-distribution, $\alpha$ is the probability or confidence level, $n$ is the degrees of freedom, $\boldsymbol{C}$ is the covariance matrix, and $\boldsymbol{a}$ is a vector of the sensitivity coefficients. Given that $\sigma_{m}^{2}$ is the variance of the slope, and $\sigma_{b}^{2}$ is the variance of the offset, the matrix math can be written as

$$
\boldsymbol{a}^{T} \boldsymbol{C a}=\left[\begin{array}{ll}
\frac{\partial y}{\partial m} & \frac{\partial y}{\partial b}
\end{array}\right]\left[\begin{array}{cc}
\sigma_{m}^{2} & \operatorname{Cov}(m, b) \\
\operatorname{Cov}(m, b) & \sigma_{b}^{2}
\end{array}\right]\left[\begin{array}{l}
\frac{\partial y}{\partial m} \\
\frac{\partial y}{\partial b}
\end{array}\right]
$$

and then simplified to the propagation of uncertainties,

$$
\boldsymbol{a}^{\boldsymbol{T}} \boldsymbol{C a}=I^{* 2} \sigma_{m}^{2}+\sigma_{b}^{2}+2 I^{*} \operatorname{Cov}(m, b) .
$$

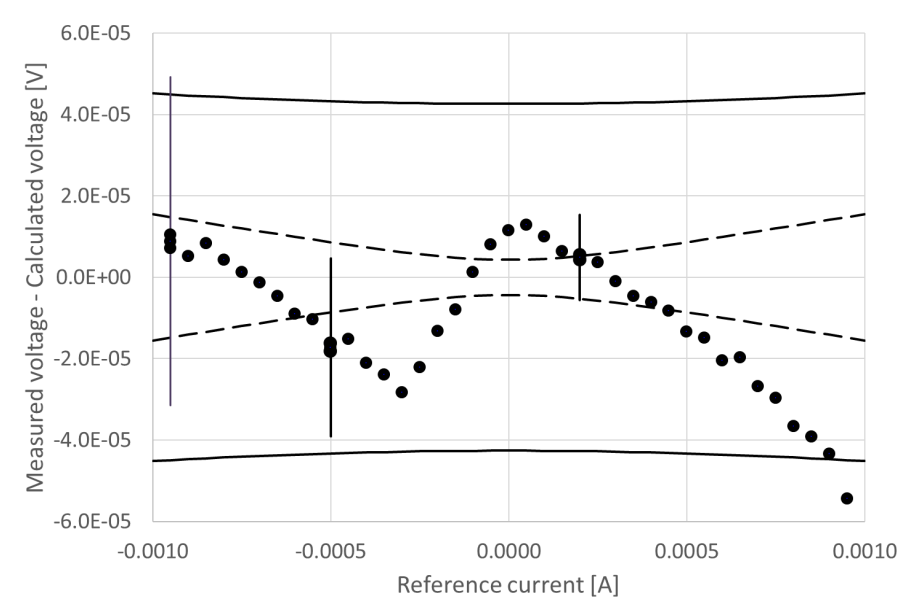

Fig. 7. Residuals for the LLS weighted fit of a DUT for $G_{m}$ [V/A] of $10^{4}$. The standard uncertainty is shown as a single bar for the data $\dagger$ points at $-0.0095 \mathrm{~A},-0.0005 \mathrm{~A}$, and $0.0002 \mathrm{~A}$. The oblong-shaped dot at these points represents the variability in the measurements. The dashed lines represent the confidence band for the results of the weighted linear fit. The prediction band is shown by the solid lines.

However, the uncertainty of the output voltage resulting from the fitting error is not captured by the confidence band. Prediction bands need to be calculated to incorporate the residuals of the fit. When a

$\doteqdot$ On April 14, 2020, the word "predication" was corrected to "prediction" throughout the article. 


\section{Journal of Research of the National Institute of Standards and Technology}

function, in this case, a linear function, is used that poorly represents the data, the residuals of the fit need to be incorporated in the fit. The prediction bands are calculated by

$$
P I\left(I^{*}\right)=t_{\alpha, n-2} \cdot \sqrt{\sum \frac{\left(y_{i}-\widehat{y_{l}}\right)^{2}}{n-2}+\boldsymbol{a}^{T} \boldsymbol{C a}},
$$

and are represented in Fig. 7 by the solid lines. Figure 8 shows the residuals for the linear fit to the data for the same DUT operating with a $G_{m}$ [V/A] of $10^{9}$. When the linear model approximates the data more accurately, the confidence bands and the prediction bands become very similar in magnitude. The standard uncertainty is shown as a single bar for the data points at $-5 \times 10^{-9} \mathrm{~A}$ and $2 \times 10^{-9} \mathrm{~A}$. The oblong shape at these points represents the variability in the measurements. The dashed line represents the confidence band for the results of the weighted linear fit. The prediction band is shown by the solid lines.

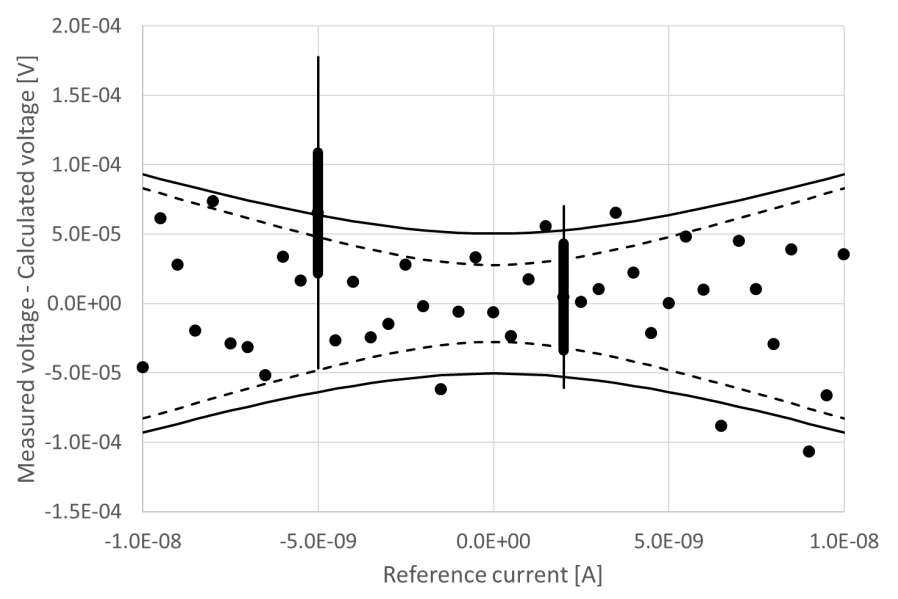

Fig. 8. Residuals for the LLS weighted fit of a DUT for $G m$ [V/A] of $10^{9}$. The standard uncertainty is shown as a single bar for the data points at $-5 \times 10^{-9} \mathrm{~A}$ and $2 \times 10^{-9} \mathrm{~A}$. The oblong shape at these points represents the variability in the measurements. The dashed lines represent the confidence band for the results of the weighted linear fit. The prediction band is shown by the solid lines.

The standard uncertainty for the output voltage as described in Fig. (8) is simplified to

$$
u(V)=\left[\left(\alpha \times\left[\left(V-b / G_{m}\right]^{2}+\beta\right)+(\gamma \times V)^{2}\right]^{-2} .\right.
$$

The $\operatorname{Cov}(m, b)$ term is removed because it is typically orders of magnitude smaller than other components. Examples of the coefficients, $\alpha, \beta$, and $\gamma$, for determining the uncertainty in the voltage due to linear fitting for the DUT are given in Table 9. The $\alpha, \beta$ coefficients are derived from the uncertainty coefficients for $m$ and $b$, respectively, and $\gamma$ is the drift in the current source calibration.

Table 9. Example DUT coefficients for the linear fitting of output voltage standard uncertainty.

\begin{tabular}{l|r|r|r|r|r|r}
\hline \multicolumn{1}{c|}{ Range Setting $^{\mathrm{a}}$} & \multicolumn{1}{c}{$1 \times 10^{4} \mathrm{~V} / \mathrm{A}$} & \multicolumn{1}{|c}{$1 \times 10^{5} \mathrm{~V} / \mathrm{A}$} & $1 \times 10^{6} \mathrm{~V} / \mathrm{A}$ & $1 \times 10^{7} \mathrm{~V} / \mathrm{A}$ & $1 \times 10^{8} \mathrm{~V} / \mathrm{A}$ & $1 \times 10^{9} \mathrm{~V} / \mathrm{A}$ \\
\hline$\alpha\left[(\mathrm{V} / \mathrm{A})^{2}\right]$ & $4.78 \mathrm{E}-05$ & $1.87 \mathrm{E}-02$ & $1.99 \mathrm{E}+00$ & $2.16 \mathrm{E}+02$ & $4.26 \mathrm{E}+04$ & $9.30 \mathrm{E}+06$ \\
\hline$\beta\left[\mathrm{V}^{2}\right]$ & $4.60 \mathrm{E}-10$ & $4.31 \mathrm{E}-10$ & $6.30 \mathrm{E}-10$ & $7.56 \mathrm{E}-10$ & $7.03 \mathrm{E}-10$ & $1.80 \mathrm{E}-09$ \\
\hline$\gamma$ & $1.34 \mathrm{E}-05$ & $1.09 \mathrm{E}-05$ & $1.38 \mathrm{E}-05$ & $1.44 \mathrm{E}-05$ & $8.93 \mathrm{E}-06$ & $7.80 \mathrm{E}-05$ \\
\hline
\end{tabular}

${ }^{\mathrm{a}} \alpha\left[(\mathrm{V} / \mathrm{A})^{2}\right]$ is the coefficient dependent on the current level measured.

$\beta\left[\mathrm{V}^{2}\right]$ is the coefficient independent of the current level measured.

$\gamma$ is from the Keithley 263 or Keithley 6430 current source drift, using calibration drift over 6 months, with the RSS of all points except zero. Large drifts are sometimes seen in DUTs gain 9 and 10.

\footnotetext{
${ }^{\top}$ Multiple corrections made on April 14, 2020: Formatting in Fig. 8 caption changed to superscript; clarified terminology in text that explains Eq. (9); clarified terminology that explains Table 9; corrected a unit in Table 9.
} 


\section{Journal of Research of the National Institute of Standards and Technology}

The uncertainty component determined from Eq. (9) is combined with the gain and offset uncertainty components, along with the uncertainty in the calibration of the voltmeter used and the standard deviation of the voltage measurements, as well as any other components required by the uncertainty analysis for the application, as described above.

\subsubsection{DUT-Other Considerations}

The offset voltage, $b$, found from the LLS weighted fit is frequently assumed to be zero and ignored, i.e., $y=G_{m} x$ following from Eq. (3). This is suitable if the measurement uncertainty $U(b)$ is larger than the offset, $b$, which is the case for gain $1 \times 10^{9} \mathrm{~V} / \mathrm{A}$ in Table 8 . This is not the case for the other gain settings in Table 8, and Eq. (4) should be used for determining the output current. For some situations, such as legacy systems, only the gain, $G_{m}$, is used, or where modest uncertainty levels are required, or for just simplifying the data analysis, the uncertainty of the offset can be expanded to cover the offset voltage.

The reported DUT gain uncertainty, $u\left(G_{m}\right)$, can vary due to a change in the noise amplification that depends on the current source output resistance, i.e., photodiode shunt resistance. The output resistances of the current sources are listed in Table 10 for each DUT gain setting. This uncertainty component should be considered by the user [3].

Table 10. Current source output resistances.

\begin{tabular}{c|r|c|c|}
\hline $\begin{array}{c}\text { DUT Gain Range } \\
{\left[\times 10^{x}\right]}\end{array}$ & $\begin{array}{c}\text { Current } \\
\text { Range }\end{array}$ & $\begin{array}{c}\text { Keithley 263 Source Output } \\
\text { Resistance [Ohms] }\end{array}$ & $\begin{array}{c}\text { Keithley 6430 Source Output } \\
\text { Resistance [Ohms] }\end{array}$ \\
\hline 3 & $10 \mathrm{~mA}$ & $1 \mathrm{E}+03$ & $1 \mathrm{E}+06$ \\
\hline 4 & $1 \mathrm{~mA}$ & $1 \mathrm{E}+04$ & $1 \mathrm{E}+07$ \\
\hline 5 & $100 \mu \mathrm{A}$ & $1 \mathrm{E}+04$ & $1 \mathrm{E}+08$ \\
\hline 6 & $10 \mu \mathrm{A}$ & $1 \mathrm{E}+05$ & $1 \mathrm{E}+09$ \\
\hline 7 & $1 \mu \mathrm{A}$ & $1 \mathrm{E}+06$ & $1 \mathrm{E}+10$ \\
\hline 8 & $100 \mathrm{nA}$ & $1 \mathrm{E}+07$ & $1 \mathrm{E}+11$ \\
\hline 9 & $10 \mathrm{nA}$ & $1 \mathrm{E}+08$ & $1 \mathrm{E}+12$ \\
\hline 10 & $1 \mathrm{nA}$ & $1 \mathrm{E}+09$ & $1 \mathrm{E}+12$ \\
\hline
\end{tabular}

\section{Measurement Service}

The NIST current-to-voltage converter calibration service is part of the calibration services offered by the Sensor Science Division in the Physical Measurement Laboratory. The service IDs and their descriptions are given in Table 11. Current fees are listed on the NIST web page, NIST service IDs 39300S and 39310C.

Table 11. Current-to-voltage converter calibration service IDs and descriptions.

\begin{tabular}{|l|l|}
\hline Service ID & Service Name and Description \\
\hline 39300 S & $\begin{array}{l}\text { Special tests of current-to-voltage converters-Customer-supplied current-to-voltage converters, commonly } \\
\text { referred to as "amplifiers" or "current preamplifiers." This calibration should be discussed with NIST staff } \\
\text { before submitting a request. }\end{array}$ \\
\hline 39310C & $\begin{array}{l}\text { Gain and linearity of current-to-voltage converters - Customer-supplied current-to-voltage converters, } \\
\text { commonly referred to as "amplifiers" or "current preamplifiers." This calibration is for specific devices that } \\
\text { can be computer controlled and have outputs between -10 V to 10 V. This calibration should be discussed } \\
\text { with NIST staff before submitting a request. }\end{array}$ \\
\hline
\end{tabular}




\subsection{Quality System}

The CVC calibration service maintains a quality management system as part of the NIST quality system. The service is assessed and meets the requirements of the International Committee for Weights and Measures (CIPM) Mutual Recognition Arrangement (MRA). The NIST quality system for calibration services is based on ISO/IEC 17025:2005 [8]. The quality management system documents specific quality policies and procedures, from calibration procedures to handling and storage of calibration items, to quality assurance, to storage and control of records.

\subsection{System Validation}

A first step in validation is to measure the TS CVC as a DUT and to verify that all the linear fit residuals are near zero, that is, within the TS CVC reproducibility uncertainties. The idea here is that by using the device that was used to calibrate the current source, then all the results should be identical to the calibration values.

A more comprehensive validation is to calibrate the Val CVC that has also been calibrated by the QMD resistance calibration service. (Both the CVCs are calibrated at the same time.) The Val CVC is measured as a DUT, and the results are compared to the resistance values given in the QED calibration report. The two results should agree to within the TS CVC uncertainties given above.

\subsection{Check Standard Current-to-Voltage Converter (CS-CVC)}

A commercial CVC (e.g., Gentec-EO model SDX-1153) that is typical of the DUTs calibrated by the CVC calibration system is used to verify that the system is in process control. When calibrations are performed, it is measured first, and the results are analyzed before any DUTs are measured. The CS-CVC reproducibility uncertainties (see Table 7 ) are used as the quality-control limits for the gain $\left(G_{m}\right)$, and the offset uncertainties, $u(b)$ (see Table 8), are used as the quality-control limits for the offset $(b)$.

\section{Calibration Procedure}

Before beginning the DUT calibration, the current source, voltmeter, CS-CVC, and DUT are powered on and allowed to warm-up per manufacturer specifications. The voltmeter autocalibration routine is executed. The CS-CVC is measured first to verify the calibration system operation. The results are analyzed automatically and compared to previous results. If the CS-CVC results are within quality system limits, the DUT is measured. The DUT results are analyzed automatically, and the calibration report is written and sent to the customer following the process detailed in the calibration service quality system.

\section{Summary}

NIST now offers a calibration service for the radiometry and photometry communities of CVCs that measure DC photocurrents in the range of $100 \mathrm{pA}$ to $1 \mathrm{~mA}$. This service provides SI traceable calibration with uncertainties lower than typically provided by manufacturers. This paper also explains the uncertainty propagation for the end user's DUT. 


\section{Appendix A: Sample Calibration Report}

A sample calibration report of a CVC for NIST service ID 39310C is shown in Fig. 9.

\section{REPORT OF CALIBRATION}

Gain and Linearity of Current-to-Voltage Converters (39310C)

For:

Submitted by:

_mfg, model:_model, serial no.:_sn

companyname

Attn:__poc

companyaddress

city,_state_zipcode

Purchase Order No.:

Calibration Performed by:

Report Approved by:

$$
\text { po (_podate) }
$$

The current-to-voltage conversion gain of the test current-to-voltage convertor (DUT) was determined using a precision current source, Keithley _csmodel, SN: _cssn, and digital voltmeter, _dvmmodel, SN: dvmsn [1]. Data was taken on each range setting with input currents set to give approximate output voltages from $-10 \mathrm{~V}$ to $10 \mathrm{~V}$ in $0.5 \mathrm{~V}$ steps. The CVC Enclosure temperature at the time of this calibration was _temp ${ }^{\circ} \mathrm{C}$, but was not used in the data analysis.

The current-to-voltage conversion (gain and offset) of the DUT is listed for each gain range setting in Table 1. The SI traceability chain and uncertainty for the current-to-voltage conversion is described in Ref. 1 and 2. The expanded uncertainty $(k=2)$ at each gain range setting for this measurement is listed in Table 1.

The standard uncertainty of the measured current by the DUT, $u(x)$, is made up of several components, including gain and offset uncertainties, voltmeter calibration, standard deviation of the voltage measurements, and the uncertainty in the voltage due to the linear gain equation fitting. Table 2 provides the standard uncertainty for the voltage due to linear fitting using the equation, $u(y)=\sqrt{\left(\alpha *[(y-b) / m]^{2}+\beta\right)+(\gamma * y)^{2}}$. The measurement results apply only to the calibration item(s) referenced in this report. This report shall not be reproduced, except in full, without the written approval of NIST.

References:

[1] Eppeldauer GP, Yoon HW, Jarrett DG, Larason TC (2013) Development of an in-situ calibration method for current-to-voltage converters for high-accuracy SI-traceable low dc current measurements. Metrologia 50(5):509-517. https://doi.org/10.1088/0026-1394/50/5/509.

[2] Eppeldauer GP (2009) Traceability of Photocurrent Measurements to Electrical Standards. Mapan-J Metrol Soc I24(3):193-202.

Table 1: Gain, offset, and expanded uncertainties $(k=2)$ of_mfg, model_model, serial no._sn

\begin{tabular}{|c|c|c|c|c|c|c|}
\hline & \multicolumn{6}{|c|}{ Linear Least Squares Weighted Fit $\left(y=G_{m} x+b\right)$} \\
\hline Range Setting & $1 \times 10^{4} \mathrm{~V} / \mathrm{A}$ & $1 \times 10^{5} \mathrm{~V} / \mathrm{A}$ & $1 \times 10^{6} \mathrm{~V} / \mathrm{A}$ & $1 \times 10^{7} \mathrm{~V} / \mathrm{A}$ & $1 \times 10^{8} \mathrm{~V} / \mathrm{A}$ & $1 \times 10^{9} \mathrm{~V} / \mathrm{A}$ \\
\hline Gain $(m)[\mathrm{V} / \mathrm{A}]$ & -10001.0525 & & & & & \\
\hline Gain $U(m)[\mathrm{V} / \mathrm{A}]$ & 0.0133 & & & & & \\
\hline Offset (b) [V] & $-1.04 \mathrm{E}-05$ & & & & & \\
\hline Offset $U(b)[\mathrm{V}]$ & $4.1 \mathrm{E}-06$ & & & & & \\
\hline
\end{tabular}

Table 2: Standard uncertainty coefficients of_mfg, model_model, serial no._sn

\begin{tabular}{|c|c|c|c|c|c|c|}
\hline \multicolumn{7}{|c|}{ Linear Least Squares Weighted Fit $\left(y=G_{m} x+b\right)$} \\
\hline Range Setting & $1 \times 10^{4} \mathrm{~V} / \mathrm{A}$ & $1 \times 10^{5} \mathrm{~V} / \mathrm{A}$ & $1 \times 10^{6} \mathrm{~V} / \mathrm{A}$ & $1 \times 10^{7} \mathrm{~V} / \mathrm{A}$ & $1 \times 10^{8} \mathrm{~V} / \mathrm{A}$ & $1 \times 10^{9} \mathrm{~V} / \mathbf{A}$ \\
\hline$\alpha\left[\mathrm{A}^{2}\right]$ & 5.57E-05 & & & & & \\
\hline$\beta\left[\mathrm{V}^{2}\right]$ & $5.30 \mathrm{E}-10$ & & & & & \\
\hline$\gamma$ & $9.61 \mathrm{E}-06$ & & & & & \\
\hline
\end{tabular}

Calibration Date:_caldate

NIST Test No.: 685/_foldernumber-_yy

Page 1 of 1

Fig. 9. Sample calibration report of a CVC for NIST service ID 39310C. 


\section{Appendix B: Updated Sample Calibration Report}

An updated sample calibration report of a CVC for NIST service ID 39310C is shown in Fig. 10.

\begin{tabular}{|c|c|}
\hline & $\begin{array}{l}\text { REPORT OF CALIBRATION } \\
\text { Gain and Linearity of Current-to-Voltage Converters (39310C) }\end{array}$ \\
\hline For: & _mfg, model:_model, serial no.:_sn \\
\hline Submitted by: & $\begin{array}{l}\text { companyname } \\
\text { Attm.:_poc } \\
\text { _companyaddress } \\
\text { _city,_state_zipcode }\end{array}$ \\
\hline Order No.: & _ordernumber (order date) eif applicable> \\
\hline Calibration Performed by: & _calstaff, Calibration Staff, Optical Radiation Group \\
\hline Report Approved by: & $\begin{array}{l}\text { grpleader, Leader, Optical Radiation Group } \\
\text { For the Director of the National Institute of Standards and Technology }\end{array}$ \\
\hline Issue Date: & _reportdate \\
\hline
\end{tabular}

The current-to-voltage conversion gain of the test current-to-voltage convertor (DUT) was determined using a precision current source, Keithley_csmodel, SN: _cssn, and digital voltmeter, _dvmmodel, SN:_dvmsn [1]. Data was taken on each range setting with input currents set to give approximate output voltages from $-10 \mathrm{~V}$ to $10 \mathrm{~V}$ in $0.5 \mathrm{~V}$ steps. The CVC Enclosure temperature at the time of this calibration was _temp " $\mathrm{C}$ but was not used in the data analysis.

The measured input current to the DUT is,

$$
I=(V-b) / G_{\mathrm{m},}
$$

where $I[\mathrm{~A}]$ is the input current to the DUT, $V[\mathrm{~V}]$ is the output voltage of the DUT, $b[\mathrm{~V}]$ is the offset, and $G_{m}[\mathrm{~V} / \mathrm{A}]$ is the measured gain. The current-to-voltage conversion (gain and offset) of the DUT is listed for each gain range setting in Table 1. The SI traceability chain and uncertainty for the current-to-voltage conversion is described in Ref. 1. The expanded uncertainty $(k=2)$ of the gain and offset at each gain range setting for this measurement is listed in Table 1 .

The standard uncertainty of the measured current by the DUT, $u(I)$, is made up of several components, including gain and offset uncertainties, voltmeter calibration, standard deviation of the voltage measurements, and the uncertainty in the offset uncertainties, voltmeter calibration, standard deviation of the voltage measurements, and the uncertainty in the
voltage due to the linear gain equation fitting. Table 1 provides coefficients for determining the uncertainty in the voltage due to linear fitting using the equation,

$$
u(V)=\left[\left(\alpha \times\left[(V-b) / G_{m}\right]^{2}+\beta\right)+(\gamma \times V)^{2}\right]^{2} .
$$

The measurement results apply only to the calibration item(s) referenced in this report. This report shall not be reproduced, except in full, without the written approval of NIST.

References:

[1] Larason T, Miller CC (2018) Gain Calibration of Current-to-Voltage Converters. J Res Natl Inst Stan 123:123019. https://doi.org/10.6028/ires.123.019.

Table 1: Gain, offset, corresponding expanded uncertainties ( $k=2)$, and coefficients for the linear fitting of output voltage standard uncertainty for_mfg, model_model, gerial no._sn

\begin{tabular}{|c|r|r|r|r|r|r|r|}
\hline $\begin{array}{c}\text { Gain Range } \\
{\left[\mathbf{1 0}^{2}\right]}\end{array}$ & $\begin{array}{c}\text { Gain }(G m) \\
{[\mathrm{V} / \mathrm{A}]}\end{array}$ & $\begin{array}{c}\text { Gain } L(\mathrm{Gm}) \\
{[\mathrm{V} / \mathrm{A}](k=2)}\end{array}$ & $\begin{array}{c}\text { Offset }(b) \\
{[\mathrm{V}]}\end{array}$ & $\begin{array}{c}\text { Offset } L(b) \\
{[\mathrm{V}](k=2)}\end{array}$ & $\begin{array}{c}\alpha \\
{\left[(\mathrm{V} / \mathrm{A})^{2}\right]}\end{array}$ & $\begin{array}{c}\beta \\
{\left[\mathrm{V}^{2}\right]}\end{array}$ & $\begin{array}{c}\boldsymbol{\gamma} \\
{[\text { unitless] }}\end{array}$ \\
\hline 4 & $-1.00004225 \mathrm{E}+4$ & $1.1 \mathrm{E}-2$ & $-8.94 \mathrm{E}-6$ & $3.6 \mathrm{E}-6$ & $3.17 \mathrm{E}-5$ & $2.02 \mathrm{E}-10$ & $1.34 \mathrm{E}-5$ \\
\hline 5 & $-1.0000222 \mathrm{E}+5$ & $2.2 \mathrm{E}-1$ & $-1.59 \mathrm{E}-5$ & $8.8 \mathrm{E}-6$ & $1.15 \mathrm{E}-2$ & $3.68 \mathrm{E}-10$ & $1.09 \mathrm{E}-5$ \\
\hline 6 & $-1.0000541 \mathrm{E}+6$ & $2.8 \mathrm{E}+0$ & $-1.36 \mathrm{E}-5$ & $1.4 \mathrm{E}-5$ & $2.02 \mathrm{E}+0$ & $2.85 \mathrm{E}-10$ & $1.38 \mathrm{E}-5$ \\
\hline 7 & $-1.0001072 \mathrm{E}+7$ & $2.8 \mathrm{E}+1$ & $-1.60 \mathrm{E}-5$ & $1.1 \mathrm{E}-5$ & $1.88 \mathrm{E}+2$ & $3.89 \mathrm{E}-10$ & $1.44 \mathrm{E}-5$ \\
\hline 8 & $-1.0001692 \mathrm{E}+8$ & $3.4 \mathrm{E}+2$ & $-2.34 \mathrm{E}-5$ & $1.7 \mathrm{E}-5$ & $3.13 \mathrm{E}+4$ & $6.15 \mathrm{E}-10$ & $8.93 \mathrm{E}-6$ \\
\hline 9 & $-1.002449 \mathrm{E}+9$ & $6.0 \mathrm{E}+3$ & $-4.15 \mathrm{E}-6$ & $2.4 \mathrm{E}-5$ & $9.08 \mathrm{E}+6$ & $1.37 \mathrm{E}-9$ & $1.38 \mathrm{E}-4$ \\
\hline
\end{tabular}

Calibration Date:_caldate Page 1 of 1

Fig. 10. Updated sample calibration report of a CVC for NIST service ID 39310C.

$\bar{\dagger}$ Appendix B added on April 14, 2020: The calibration report was updated to clarify the data provided. 


\section{Acknowledgments}

The authors acknowledge George P. Eppeldauer, Howard W. Yoon, Shamith U. Payagala, and Dean G. Jarrett for their collaboration over many years to help evolve a simple gain validation setup into the NIST CVC calibration service. The authors also thank two Summer High School Intern Program (SHIP) students, Aleksandar Antic (2016) and Peter Mnev (2017), who prototyped an automated system to change the rotary-gain switches of manually switched CVCs. They designed, built, and tested the hardware and software using an inexpensive microcontroller and stepper motor, which in the future will save many hours of manually changing gain switches.

\section{References}

[1] Sipila P, Rajala R, Karha P, Manninen A, Ikonen E (2005) Calibration of current-to-voltage converters for radiometric applications at picoampere level. 9th International Conference on New Developments and Application in Optical Radiometry (NEWRAD 2005), ed Grobner J, pp 223-224.

[2] Yoon HW, Eppeldauer GP, Jarrett DG, Larason TC, Kim WS (2010) Calibrations of current-to-voltage transimpedance amplifiers using electrical standards. 2010 Conference on Precision Electromagnetic Measurements (CPEM), pp 753-754. https://doi.org/10.1109/CPEM.2010.5544230

[3] Eppeldauer GP, Yoon HW, Jarrett DG, Larason TC (2013) Development of an in situ calibration method for current-to-voltage converters for high-accuracy SI-traceable low dc current measurements. Metrologia 50(5):509-517. https://doi.org/10.1088/0026-1394/50/5/509

[4] Larason TC, Eppeldauer GP, Yoon HW, Jarrett DG (2014) SI-traceable calibrations and nonlinearity measurements of currentto-voltage convertors. 12th international Conference on New Developments and Applications in Optical Radiometry (NEWRAD 2014), ed Ikonen E, pp 192-193. Available at http://newrad2014.aalto.fi/Newrad2014_Proceedings.pdf

[5] Eppeldauer GP (2009) Traceability of photocurrent measurements to electrical standards. MAPAN-Journal of the Metrology Society of India 24(3):193-202. https://doi.org/10.1007/s12647-009-0023-9

[6] Elmquist RE, Jarrett DG, Jones GR, Kraft ME, Shields SH, Dziuba RF (2003) NIST Measurement Service for DC Standard Resistors. ((National Institute of Standards and Technology, Gaithersburg, MD), NIST Technical Note (TN) 1458. https://doi.org/10.6028/NIST.TN.1458

[7] Hamilton CA, Lloyd FL, Chieh K, Goeke WC (1989) A 10-V Josephson voltage standard. IEEE Transactions on Instrumentation and Measurement 38(2):314-316. https://doi.org/10.1109/19.192296

[8] International Organization for Standardization (2005) ISO/IEC 17025:2005-General requirements for the competence of testing and calibration laboratories (International Organization for Standardization, Geneva, Switzerland). https://www.iso.org/standard/39883.html

About the authors: Thomas C. Larason is an electronics engineer in the Optical Radiation Group of the Sensor Science Division of the Physical Measurement Laboratory, NIST. His research interests are detectors of ultraviolet, visible, and near-infrared light. Additional research areas include the measurement of photocurrent and developing new transfer standards. He has collaborated with both university and industry researchers on various projects, including ultraviolet light sensors used for the inactivation of pathogens for drinking water and remote sensing.

C. Cameron Miller is a research chemist and group leader of the Optical Radiation Group of the Sensor Science Division of the Physical Measurement Laboratory, NIST. His research areas include all aspects of photometry, retroreflection, measurement uncertainty, and vision science applied to lighting.

The National Institute of Standards and Technology is an agency of the U.S. Department of Commerce. 